observation. Besides the present study discovered simultaneously that small dosage and large dosage of LG could lower the patient's FIB level, which is statistically different when compared with that of the control group.

LG can safely and efficiently lower the plasma PAI-1 activity level of type $2 \mathrm{DM}$ patients, and large dosage of LG could be markedly effective. And so, being cheap in price, with no adverse reaction, LG is worth popularizing in clinical practice.

\section{REFERENCES}

1. CHEN YL, HAN XY, MAO TS. Study on the relationship of PAI-1 and vascular lesion of type 2 DM. Clin Assembl $1999 ; 14(8): 347-349$.

2. SHANG SH, NING G, DAI R, et al. Relationship between PAI-1 of NIDDM and hyper-insulinism and insulin resistance. Chin J Endocrinol Metab 1997;13(1) : 68 .

3. PENG YW, NING G, LI SG, et al. Exploration on re- lationship of PAI-1 of NIDDM and complicated CHD. Chin Chronic Dis Prev Treat 1998;6 (2) : 62-64.

4. Tomookas Border WA, Marshall BC, et al. Glomerular matrix accumulation is linked to inhibition of the plasmin protease system. Kidney Int $1992 ; 42: 1462-1469$.

5. Loskutoff DJ. Regulation of PAI-1 gene expression. Fibrinolysis $1991 ; 5(2): 197-199$.

6. Emeis JJ, Kooistra T. Interleukin 1 and lipopolysaccharide induce an inhibitor of tissue-type plasminogen activator in cultured endothelial cells. J Exp Med 1986;163 (5) : $1260-1266$.

7. Cho YW, Yang DH, Oh DY, et al. Plasma t-PA and PAI antigen concentrations in non-insulin dependent diabetic patients: Implication for diabetics retinopathy. Diabetes Res Clin Pract 1994;22: 123-128.

8. Tonny J, Jens BK, Bo feldt R, et al. Features of endothelial dysfunction in early diabetic nephropathy. Lancet $1989 ; 4: 461-463$.

9. Tsutomu H, Kouichi K, Yasuneri M, et al. Albuminuria is directly associated with increased plasma PAI-1 and factor VII levels in NIDDM patients. Diabetes Res Clin Pract $1997 ; 36(1): 11-18$.

10. RUAN ZR, SONG JX, DENG ZD. Study on mechanism of ligustrazine against thrombosis. Chin J Atherosclerosis $1998 ; 6(4): 297-300$.

(Received June 4, 2003)

\title{
Clinical Observation on 103 Patients of Severe Acute Respiratory Syndrome Treated by Integrative Traditional Chinese and Western Medicine
}

\author{
LIN Lin (林 琳), HAN Yun (韩 云), YANG Zhi-min (杨志敏), LIU Wei-sheng (刘伟胜), \\ ZHANG Min-zhou（张敏州), TANG Guang-hua（唐光华), and XU Yin-ji（许银姬）
}

\section{Guangdong Provincial Hospital of Traditional Chinese Medicine, Guangzhou (510120)}

Objective: To observe the effect of 103 patients of severe acute respiratory syndrome (SARS) treated by integrative traditional Chinese and western medicine. Methods: Alimentotherapy, respiratory auxiliaring ventilation, anti-infective and glucocorticoid methods were used in western medicine; Chinese herbal medicine was used according to syndrome differentiation in traditional Chinese medicine. Descriptive statistical analyses were performed. Results: Of the 103 patients, 77 were identified as severe cases and 29 were admitted to the intensive care $\mathbf{u}^{-}$ nit. A total of 96 patients $(93.2 \%)$ were cured, 7 patients died $(6.8 \%)$. The mean time between onset of fever and improvement was $6.72 \pm 3.95$ days; 94 successful responses to therapy could be demonstrated by serial chest radiographs showing the resolution of lung opacities during 18.13 \pm 8.99 days, 2 of whom showed fibroid cord-like changes. Conclusion: In terms of traditional Chinese medicine theory, SARS is referred to "infectious febrile disease", the therapeutic strategies of integrative traditional Chinese and western on SARS have been shown effective, and traditional Chinese medicine played a positive role in it.

Original article on CJIM (Chin) $2003 ; 23(6): 409$ 